\title{
Public Health Aspects of Refugee Health: A Review of the Evidence on Health Status for Refugees Globally
}

\author{
Article by Krishan Puri \\ Master of Public Health, Texila American University, Nepal \\ E-mail: krishnjames77@gmail.com
}

\begin{abstract}
Introduction: Asylum seekers and refugees are identified as those who did not make voluntary choice to leave their origin country and cannot return home safely. Internally displaced persons and refuges are extremely vulnerable to human rights abuses, especially the absence and denial of mental and physical health care. For more than 50years, the fundamental framework of refugee protection has been established and accepted globally. The lack of respect to human rights of refugees and failure to provide adequate humanitarian help such as health care. The Geneva Conventions, the Universal Declarations of Human Rights, Statute of the office of the United nations High Commissioner for Refugees, and the Convention Relating to the Status of Stateless Persons, all establish international standards for private and governments organizations that set guidelines for assimilation and repatriation of refugees that create international standards.

Methods: The study was conducted through a systematic literature review of articles dating between 2001 and 2015 on Embase, PsychInfo, Medline and Cochrane Controlled Trials, UNHCR, IOM and World Health Organization databases. The study decided on the articles to review by reading abstracts to determine inclusion of data about the health status of either the internally displaced person or the refugees. The abstracts were selected randomly and independently. A limited random search of the reference lists of all included studies was also undertaken. And also few English language studies of evaluated primary health care models of care for refugees in developed countries of resettlement were included.

Results: The internally displaced people's and refugees are extremely vulnerable to human rights abuses From the research, it is clear that across the globe, access of primary healthcare amongst the refugees is overwhelmingly shaped by the regulations of the migration process and legal frameworks of individual states and nations. The study discusses that there is a primary need for advanced communication with refugees and coordination of activities between agencies either public or private within and beyond the health care structure. The study seeks to unveil the channels that create the neglect of refugees' right to a chance of survival. The study recommends that improved data are imperative towards supporting inter-sectorial work in addressing health care needs of refugees.
\end{abstract}

Keywords: Refugee health, public health, migration health, healthcare, global

\section{Introduction}

\section{Problem statement}

Globally, migration is a critical public health, political and social challenge. The number of international migrants globally rose by over 77 million between the year 1990 and 2013. Europe is identified as the leading continent in receiving international migrants (Janmyr, 2014). More specifically, there was an approximate half a million people who sought asylum in Europe in 2013 which according to the United Nations High Commissioner for Refugees (UNHCR) represents a 32\% percent increase since 2012. According to the research, Europe involuntarily creates a safe haven for people on the run. Research shows government and economic stability as one of the main characteristics of refuged paces. Evidently, as the immigration laws constantly tend to have strategic bottlenecks to reduce the influx in refugee camps other aspects fuel the movement. Insecurity in the neighboring areas slows down the 
much effort invested in the same. Currently, there is lack of evidence that the global burden of refugees is likely to fall. The ongoing crisis in Aegean and southern Mediterranean nations suggests the exact opposite. The situations in Turkey, Iraq, Syria, and Somalia amongst others indicates that the rates of refugees will keep growing. It is thus important for host nations in collaboration with global agencies to focus on availing equitable access to health promotion and disease prevention and care to the migrants.

By international law and standards, refugees are owed protection including access to health services from their first nation of registration for asylum. However, such rights may not be provided at the asylum determination stage. The internally displaced people and refugees are extremely vulnerable to human rights abuses, particularly the denial of mental and physical healthcare. For over 50 years, the basic framework of protecting refugees has been established and accepted globally. There are however signs indicating that there is little commitment towards providing adequate humanitarian assistance and respect of the human rights of refugees which includes health care. Several protocols and conventions such as the Universal Declaration of Human Rights, the Geneva Conventions, the Convention Relating to the Status of Stateless Persons and the Statute of the Office of the United Nations High Commissioner for Refugees. All these set standards that should be abided to by private and government organizations. This creates the idea that the set regulations and standards on service delivery to such people has few loopholes that leak out the quality and quantity of service and material delivery to aid daily survival needs. This study seeks to collect literature evidence on the global health status, which will indicate the failure or success of the international and state protocols and conventions in the public health front.

\section{Significance and structure of the study}

The public health standards for the refugees are rarely enforced fully. According to a survey on the causes of increased refugee immigration, organization with the mandate to provide and maintain a sanitized environment fail to do the same due to a constant budgetary strain by the radical growth in population of both the local citizens and the refugees in the camps. The systematic literature review seeks to detail the problems that come up in the absence of full implementation as well as serve refugee needs in their interim. To meet that need, the structure will be organized in the following five fronts;

Mental health: Naturally, refugees are prey to climates of violence that have the potential to damage the status of their mental health and this can proceed to cause Post Traumatic Stress Disorder (PTSD). In essence, therefore, the study will collect literature evidence on the issue that while humanitarian aid mainly focuses on the immediate physical needs of refugees such as shelter, food, and clean water, there is a chance that mental health is overlooked.

Children: Juvenile refugees are often in potential threat of hazardous labor conditions, sexual and physical abuse. The practical dimensions on this problem will be addressed.

Women: refugee women are in typical need of basic health care which includes education on reproductive health information or family planning. The paper will analyze the morbidity and mortality of women refugees that will be essential in calling attention to the immediate need for public health intervention.

Africa: Africa offers a special interest due to many wars, natural disasters, and political instability that results to large numbers of internally displaced people and refugees. Additionally, Africa is faced by financial crises making states render them of incapability to address the challenge adequately.

Europe and America: In the last decade, Europe has been receiving high levels of refugees more than any other continent. As a result, the study will shed light on how the public health issue of the immigrants is being handled and thus draw comparisons to Africa.

\section{Study methodology}

The study is a systematic literature review. This review primarily refers to statistics and articles referred to or financed by United Nations (UN) agencies and more specifically the 
International Organization for Migration (IOM) and United Nations High Commissioners for Refugees (UNHCR). This determines the databases to be selected as recommended by the international agencies which will be examined using headings search and keywords. Through this approach, the researcher will be in position to summarize findings in studies where the methods of study are diverse and integrate quantitative data across studies where similar outcome measures have been adopted.

\section{Scholarly papers identification}

The researcher utilized six electronic databases; Cochrane Library (2004- 2015), National Center for Biotechnology (2004- 2015), ScienceDirect (2004- 2015), Web of Science (20042015), ProQuest (2004- 2015) and PubMed (2004- 2015). The years of publication were restricted to the last decade which ensures that the data is current and comparable. Public health measures included the mortality and morbidity rates in amongst the refugees and internally displaced persons. Due to language barrier, the articles were be restricted to English and to the developed and developing countries to allow for comparisons between the nations. Secondary references were then gathered from the primary sources.

\section{Selection criteria}

The study decided on the articles to review by reading abstracts to determine inclusion of data about the health status of either the internally displaced person or the refugees. The abstracts were selected randomly and independently. The information was then coded after extraction. The coding was categorized under the aim of the study, study design, study population typology, demographic characteristics, intervention type, study measure type, summary of the results, main outcomes, strategy adopted in sampling, and the response rate and sample size, and the demographics.

\section{Results}

As the figure below indicates (acquired from the Migration Policy Institute, 2015), the rates of refugees has been growing gradually across all nations but mainly across Europe;

\begin{tabular}{|c|c|c|c|c|c|c|c|c|}
\hline \multicolumn{3}{|c|}{2015} & \multicolumn{3}{|c|}{2014} & \multicolumn{3}{|c|}{2013} \\
\hline Country & Number & Percent & Country & Number & Percent & Country & Number & Percent \\
\hline Burma & 18,386 & 26.3 & Iraq & 19,769 & 28.2 & Iraq & 19,488 & 27.9 \\
\hline Iraq & 12,676 & 18.1 & Burma & 14,598 & 20.9 & Burma & 16,299 & 23.3 \\
\hline Somalia & 8,858 & 12.7 & Somalia & 9,000 & 12.9 & Bhutan & 9,134 & 13.1 \\
\hline Dem. Rep. Congo & 7,876 & 11.3 & Bhutan & 8,434 & 12.1 & Somalia & 7,608 & 10.9 \\
\hline Bhutan & 5,775 & 8.3 & Dem. Rep. Congo & 4,540 & 6.5 & Cuba & 4,205 & 6.0 \\
\hline Iran & 3,109 & 4.4 & Cuba & 4,062 & 5.8 & Iran & 2,578 & 3.7 \\
\hline Syria & 1,682 & 2.4 & Iran & 2,846 & 4.1 & Dem. Rep. Congo & 2,563 & 3.7 \\
\hline Eritrea & 1,596 & 2.3 & Eritrea & 1,488 & 2.1 & Sudan & 2,160 & 3.1 \\
\hline Sudan & 1,578 & 2.3 & Sudan & 1,315 & 1.9 & Eritrea & 1,824 & 2.6 \\
\hline Cuba & 1,527 & 2.2 & Afghanistan & 753 & 1.1 & Ethiopia & 765 & 1.1 \\
\hline $\begin{array}{l}\text { All other countries, } \\
\text { including unknown }\end{array}$ & 6,870 & 9.8 & $\begin{array}{l}\text { All other countries, } \\
\text { including unknown }\end{array}$ & 3,182 & 4.5 & $\begin{array}{l}\text { All other countries, } \\
\text { including unknown }\end{array}$ & 3,302 & 4.7 \\
\hline Total & 69,933 & 100.0 & Total & 69,987 & 100.0 & Total & 69,926 & 100.0 \\
\hline
\end{tabular}

\section{Mental health status}

The prevalence of mental distress is higher among the refugees when compared to the nonrefugees (Bergen, 2004). Asylum seekers seem to portray higher risks than the refugees do. The risk factors associated with poor mental health among the refugees include lack of social support after forced migration, older age, trauma experiences, and being a woman (Kemp \& Rasbridge, 2004). As refugees fled from Syria to Lebanon, the laws put in place by the Lebanon government denied foreigners without passports to work in the country. In such a state, refugees bear more than the plight of separation from family and home. They also live 
through fear, despair, false hope from unending negotiations between their country of origin and organizations seeking to get back home. According to psychologists, separation from family or friend and rejection from all ends create a high risk of mental instability. The mind then rests on the support of racism, death threats, human trafficking, and organ theft among some of the basic problems stated out in the statured laws and regulations when it comes to service delivery to the refugees.

Looking into the same, as host governments and other relative organizations go out of their way to provide a healthy environment, many issues arise due to the changing times. Therefore, funds directed towards aid become unutilized due to the unattended and still strains not mentions or catered to in the operational structure. Besides focusing on offering material aid to the women and children in refugee camps such as sanitary items, organization overlook some facts as teaching the women and children how to use these items. On the same, some of the refugees, if not all, seek explanations as to why they are in their current state and to some as orphans in the camps, guidance and counselling should come in. Over the long term, the mental health appears to get worse, which is a result of lack of education, and employment that adds on the stress experienced by the refugees. Problems in the camp appear to be cyclic (Bergen, Heredia, \& Schouler-Ocak, 2014). For the host organizations to handle all issues regarding public health among the refugees, the whole idea requires an approach from a very different angle. When refugees settle in the host countries, governments and the involved organizations should look into the matter by creating a good environment to enable them to get back on their feet and fend for themselves.

\section{Children health status}

In majority of the refugee camps worldwide, children accrue to almost half the population of refugees. This follows the fact that most of the displaced people are in groups of families, large families. Moreover, when these people are in camps, there is little or no birth control knowledge dispatched to them. In order to have sufficient funds to cater for the whole population in the camps, it is crucial to monitor the population growth in the camps against the set budget. Children are the most vulnerable in these camps due to their susceptibility to cold, diseases, and hunger among other problems. It becomes a challenge for aiding organizations to set up a structured flow of material and service aid to reach everyone in these camps. Children in refugee camps are entitled to equal rights and opportunities as ones that are not. As much as allocation of the aid flowing in is with regard to its scarcity, priority becomes an important fact. Children require not only food and shelter, but security is crucial.

Children in these camps are vulnerable to kidnappers, sexual and gender risks, and killers. The structures set up to shelter refugees in host countries neglect some minor issues that mold into bigger problems (Segal \& Elliott, 2012). These camps host people from all lifestyles. Therefore, there comes a high risk of diseases: airborne and sexual. In both cases, children are at a high risk of contraction. Many of these camps lack in quality facilities like screening centers, which are important to distinguish the types and number of diseases to treat and ones to quarantine. Specifically to children, refugee camps lack in regular immunization and maternal care. Research shows that these camps can be in existence up to 30 years and more. This means that refugee camps can see a more than a life's time. The quality of natal and maternal care in these camps being below standard reflects on the standard of living in them. The distribution and monitoring structure in the food sector also neglects nutrition, which is important to both growing children and adults. Having a regular or occasional supply of food id never enough in such cases. This is especially because of the environment that these children live in. Unlike a normal child, one in a refugee camp is open to more risks. According to a research, a child's health status highly depends on the kind of education he or she gets regarding maintaining a healthy lifestyle. A number of camps directs its time, attention and funds on the basic needs in a bid to cater for all. It breaks down to more than basic needs as food and shelter when aiming for better results. 


\section{Women health status}

Refugee camps have a generalized management plan that bundles people up in clusters. This suppresses some of the women needs in the camps. Being the most affected, women, and their children require extra attention and care. Women in refugee camps go through a number of health related problems. Depending on the variation in level of services available, women need maternal care for expectant mothers. This is important because in the end it saves more than a life. It is important for the camp managers to carry out a fully detailed population census. Having a detailed record of everyone in the camp gives a clear path in creating health and sanitation budgets. Expectant women in many camps lack regular clinic checkups to monitor growth progress of their infants. In addition, women in general in many camps especially in Africa, lack a regular supply of sanitary pads. Depending on the number of women and girls in the camp, the reimbursement period and quantity need to work out a balance. Its importance reflects in maintaining healthy standards during distribution of sanitary pads, and disposal. Despite the basic health care, women in refugee camps require education on health issues such as family planning and reproduction care (Gebreiyosus, 2014). Women in refugee camps undergo a lot of trauma and abuse from men in the same camps and locals in the community. It becomes difficult to protect them from such risks and injustices. Women in these camps are the overworked gender. In many camps, the local community takes advantage of the cheap labor from refugees. In the end, women and children work for little or no pay at the mercy of the local community. Subjected to such labor conditions and unknown health hazards just to fend for their families puts both the women and children at risk.

\section{Health status in african refugees and internally displaced persons' camps}

In Africa, the rise in number of refugees is rampant due to the many wars, political instability, and financial crises. This becomes a major problem when the governments in African countries become incapable of funding and controlling the case. Internally displaced people develop diseases due to inadequate or no healthcare facilities, which then spread easily around the country. A record problem is the spread of sexually transmitted diseases (In Furman, In Epps, \& In Lamphear, 2016). Financial struggles in Africa force refugees indulge in sex trafficking to earn a living. Huge numbers result in the same creating a stringed death toll, which includes the locals. When refugees mix up with the locals, it creates a security risk because the refugees will be forced to indulge in any activity for a dime. Such activities may involve dealings in arms, robbery, and drugs. This threatens both local and refugees' health status in the end.

\section{Health status in refugee and asylum seekers in europe and america}

Questions arise when it comes to international law, both for and against the refugees. Despite the risks posed to the host country when tending to refugees, certain issues need to be set clear to ease the approach to aid (Janmyr, 2014). In Europe and America, refugees seek protection and aid with varied motives behind them. A case in the recent years where Europe's economic drop pointing to the increased refugee population in the continent. Most of these refugees come from underdeveloped countries, seeking better standards of living. In turn, health risks come in where lack of jobs due to nationality leads them to settle for anything. These refugees are used as drug mules and prostitutes (Nair, \& Sen, 2007).

\section{Discussion}

The research shows that conditions in refugee camps are not a choice, but the closest option to survival. However, conditions in the camps ought to be better than other options. Refugee management need to focus on more issues not just food and shelter. Structural organization in the refugee camps need to incorporate mental health care to control the fear, despair, and rejection that these people face. These measures need, not only come from the management, but also from the peers among the people in the camps. To do so, scheduled 
programs can help create a positive routine to enhance team building and nature care among the refugees themselves.

Additionally, health care centers in the camps need to be readily available and mobile. To reach all needy people in the area, refugee management teams need to organize regular visits in the tents or clusters to offer medical care and health tips to the refugees. This will create a systematic approach to the problem at hand and make the refugees feel less threatened in the environment and more welcome to build the community. The management should have paying labor opportunities for the refugees in the camp to earn a living in a bid to get on their feet again.

Refugee camp management need to offer ample security to the people in the camps. Many times locals blend in as refugees and receive aid in material terms, which they later sell to the refugees, payable in labor terms. This creates a shortage in aid and a conflict in interest. Management teams need to create a barrier around the shelters and have a detailed census database to avoid misallocation of resources in the camps. Security also extends to the refugee community in the camps. The managers ought to protect the women and children from sexual abuse and the community as a whole from violence. Within the camp, there may be a varied number of races. Therefore, the management should separate people within the camp to avoid racial conflicts.

Refugee camps should have disease screening centers to avoid taking in contagious diseases, which puts the whole nation at risk. Camps are easy breading environments for catastrophes. Therefore, local governments in conjunction with the aid groups ought to have camp setups on the go to control influx of refugee population and monitor the same.

\section{Conclusion}

The strategic and systematic literature review has relied heavily on migration policy institute and United Health organizations in determining the appropriate articles to offer quality and timely information. Through the analysis conducted, it is clear that the state of being a refugee and asylum seekers physically and emotionally depreciates a human being. The migrants and refugees experiences a unique and complex health problems which can be met by primary health care services. This study goes further in identifying the specific strategies required to provide accessible and well-coordinated care for refugees. Through the analysis, the dependent of dependent and their parents makes them vulnerable. Women are more prone to vulnerability through their basic health sex needs. While men are minimally affected, they join the statistics that clearly indicate the act of being a refugee is a contributor in causing post-dramatic stress, chronic stress and physical injury. These are negative indicators of the mental health of the people in the communities. Therefore, this study recommends that there should be implementation of new rules and policies be introduced and the previous ones implemented full which is a promise of improved mental health statistics of all individuals. Furthermore, the study concludes by requesting for more and mainly specific researches on the same matter to be cleared and elaborated further.

\section{References}

[1]. Akresh, I. R., \& Frank, R. (2008). Health selection among new immigrants. American Journal of Public Health, 98(1), 2058-2064.

[2]. Bergen, D. D., Heredia, M. A., \& Schouler-Ocak, M. (2014). Suicidal behavior of immigrants and ethnic minorities in Europe.

[3]. Bowers EJ, Cheng I-H: Meeting the primary health care needs of refugees and asylum seekers. Primary Health Care Research and Information Service: Research Roundup. 2010, 16.

[4]. Clark RC, Mytton J. Estimating infectious disease in UK asylum seekers and refugees: a systematic review of prevalence studies. Journal of Public Health 2007 Dec;29(4):420-428 (open access)

[5]. Department of Immigration and Border Protection: Fact sheet 60 - Australia's refugee and humanitarian program. 2010, Canberra: Australian Government, Department of Immigration and 
Border Protection Harris MF, Telfer BL: The health needs of asylum seekers living in the community. Med J Aust. 2001, 175: 589-593.

[6]. Evans, J. (1987). Introduction: migration and health. International Migration Review, 21(3), v-xiv.

[7]. Feldman R: Primary health care for refugees and asylum seekers: a review of the literature and a framework for services. Public Health. 2006, 120

[8]. Furman, R., In Epps, D., \& In Lamphear, G. (2016). Detaining the immigrant other: Global and transnational issues.

[9]. Fazel M., Reed R., Panter-Brick C., Stein A., Mental health of displaced and refugee children resettled in high-income countries: risk and protective factors The Lancet 2011 379(9812):266-282.

[10]. Fazel M, Wheeler J, Danesh J. Prevalence of serious mental disorder in 7000 refugees resettled in western countries: a systematic review. Lancet 2005 Apr 9-15;365(9467):1309-1314

[11]. Filges T., Montgomery E., Kastrup M., Klint Jørgensen A.M. The impact of detention on the health of asylum seekers: A systematic review Campbell Collaboration Library 2015-09-01 Volume 11, number 13.

[12]. Gagnon AJ, Merry L. and Robinson C. (2002). A systematic review of refugee women's reproductive health. Refuge: Canada's Journal on Refugees 2002; 21(1):6-17

[13]. Gebreiyosus, Y. (2014). Women in African Refugee Camps. Hamburg: DiplomicaVerlag.

[14]. Harris MF, Harris E, Roland M: Access to primary health care: three challenges to equity. Aust J Prim Health. 2004, 10 (3): 21-29.

[15]. Hadgkiss EJ, Renzaho AMN. The physical health status, service utilisation and barriers to accessing care for asylum seekers residing in the community: a systematic review of the literature. Australian Health Review 2014 May;38(2):142-159 (open access)

[16]. Hyman, I., \& Jackson, B. (2010). The healthy immigrant effect: a temporary phenomenon. Health Policy Research Bulletin, 17, 17-21.

[17]. Janmyr, M. (2014). Protecting civilians in refugee camps: Unable and unwilling states, UNHCR and international responsibility. Leiden: Martinus Nijhoff Publishers.

[18]. Kemp, C., \& Rasbridge, L. A. (2004). Refugee and immigrant health: A handbook for health professionals. New York: Cambridge University Press.

[19]. Le Feuvre P: How primary care services can incorporate refugee health care. Med ConflSurviv. 2001, 17: 131-136.

[20]. Muggah, E., Dahrouge, S., \& Hogg, W. (2012). Access to primary health care for immigrants: results of a patient survey conducted in 137 primary care practices in Ontario, Canada. BMC Family Practice.

[21]. Nair, P. M., \& Sen, S. (2007). Trafficking in women and children in India. New Delhi: Orient Longman.

[22]. Noymer, A., \& Lee, R. (2013). Immigrant health around the world: evidence from the World Values Survey. Journal of Immigrant \& Minority Health, 15(3), 614-623.

[23]. Norredam M, Nielsen SS, Krasnik A: Migrants' utilization of somatic healthcare services in Europe-a systematic review. The Eur J Public Health. 2009, 20: 555-563.

[24]. Owen A, Grootemaat P, Samsa P, Fildes D, Eager K: A review of the literature and practice on models of care for refugee health. 2009, Cenre for Heatlh Service Development: University of Wollongong

[25]. Ott E., Montgomery P., Interventions to improve the economic self-sufficiency and well-being of resettled refugees: A systematic review. Campbell Collaboration Library 2015-01-02 Volume 11, number 4.

[26]. Pooley J.A., Sims K. Posttraumatic growth amongst refugee populations: A systematic review. Chapter 19 of The Routledge International Handbook of Psychosocial Resilience. 2016.

[27]. Reed R., Fazel M., Jones L., Panter-Brick C., Stein A., Mental health of displaced and refugee children resettled in low and middle-income countries: risk and protective factors The Lancet 2011 379(9812):250-265.

[28]. Segal, U. A., \& Elliott, D. (2012). Refugees worldwide: Vol. 4. Santa Barbara, Calif: Praeger.

[29]. Tyrer R.A., Fazel M. hSchool and community-based interventions for refugee and asylum seeking children: A systematic review Published February 24, 2014. Plos One 9(2), e89359. 
Texila International Journal of Public Health

Volume 4, Issue 4, Dec 2016

[30]. United Nations High Commissioner for Refugees: Asylum levels and trends in industrialized countries, first half, 2012: statistical overview of asylum applications lodged in Europe and selected non-European countries.

[31]. United Nations High Commissioner for Refugee: The 1951 Convention Relating to the Status of the Refugees and Its 1967 Protocol. 2011, Geneva, Switzerland: United Nations High Commissioner for Refugees.

[32]. United Nations High Commissioner for Refugees: Refugee resettlement: an international handbook to guide reception and integration. 2002, Geneva: United Nations High Commissioner for Refugees.

[33]. United Nations High Commissioner for Refugees: Frequently asked questions about resettlement. 2012.

[34]. Victorian Foundation for Survivors of Torture: Towards a health strategy for refugees and asylum seekers in Victoria. 2004, Victoria: Victorian Foundation for Survivors of Torture. 